\title{
Diagnosis and Risk Factors of Advanced Cancers in Ethiopia
}

\author{
Samrawit Solomon ${ }^{1}$, Wudeneh Mulugeta ${ }^{2}$ \\ 'Department of Public Health, St. Paul's Hospital Millennium Medical College, Addis Ababa, Ethiopia, ${ }^{2}$ Department of Medicine, Cambridge Health \\ Alliance, Cambridge, MA, USA
}

\begin{abstract}
Background: Cancer is one of the leading causes of morbidity and mortality worldwide. Yet, limited is known about patterns of cancer and risk factors for advanced stage cancers in Ethiopia.

Methods: A cross-sectional study was conducted on 919 patients with biopsy-confirmed cancers at Tikur Anbessa Hospital in Ethiopia, 2010 to 2014. Pearson chi-square test, $t$-test, analysis of variance and multivariate logistic regression analyses were performed.

Results: The majority of the patients were females $(72.4 \%)$. The commonest malignancies among males were bone and soft tissue (16.5\%), colorectal $(12.2 \%)$, and esophageal $(9.1 \%)$. Among females, the most common cancers were cervical $(39.7 \%)$, breast (18.3\%), and ovarian $(7.1 \%)$; of these, $41.7 \%, 59.0 \%$, and $42.6 \%$ were diagnosed at advanced stages, respectively. Females had more advanced stage cancers at diagnosis than males $(37.6 \%$ vs. $24.8 \%, P<0.01)$. Among males, $46.7 \%$ of prostate and $29.0 \%$ of colorectal cancers were in advanced stages at the time of diagnosis. Delay in presentation from onset of symptoms was associated with advanced cancer among females $(\mathrm{OR}=3.21 ; 95 \% \mathrm{Cl}=1.69-6.10)$. Prostate cancer among males $(\mathrm{OR}=5.22 ; 95 \% \mathrm{Cl}=1.26-21.60)$ and breast cancer among females $(\mathrm{OR}=1.93 ; 95 \% \mathrm{Cl}=1.23-3.03)$ were more likely to be diagnosed at advanced stages.

Conclusions: Cancers with effective screening tests are common in Ethiopia and significant proportions of these were diagnosed at advanced stages, typically several months after onset of symptoms. Timely access to preventive care along with effective educational and screening strategies is needed in Ethiopia for early detection and treatment of common malignancies, such as cervical, breast and colorectal cancers.
\end{abstract}

(J Cancer Prev 2019;24:163-172)

Key Words: Neoplasm staging, Neoplasms

\section{INTRODUCTION}

Non-communicable diseases are the leading causes of death globally, killing more people each year than all other causes combined. Of the 57 million deaths that occurred globally in 2008, 36 million were due to non-communicable diseases comprising mainly cardiovascular diseases, cancers, diabetes, and chronic lung diseases [1]. The combined burden of these diseases is rising fastest among the lower-income countries, populations, and communities [2]. Contrary to popular opinion, available data demonstrate that nearly $80 \%$ of deaths due to non-communicable diseases occur in low- and middle-income countries [3]. In 2011, the World Health Organization [4] estimated that $34 \%$ of the Ethiopian population died from non-communicable diseases, with a national cardiovascular disease prevalence of $15 \%$, cancer and chronic obstructive pulmonary disease prevalence of $4 \%$ each, and diabetes mellitus prevalence of $2 \%$. Cancer is the second largest contributor to non-communicable disease deaths and causes a great deal of suffering worldwide [5].

Cancer is a leading cause of disease worldwide with estimated 14.1 million new cancer cases occurring in 2012 [6]. It is now the third leading cause of death worldwide with 8.2 million deaths in 2012 [6]. More than half of all cancer deaths each year are due to

Received June 19, 2019, Revised September 2, 2019, Accepted September 14, 2019

Correspondence to: Samrawit Solomon

E-mail: samrawit.solomon@sphmmc.edu.et, ORCID: Samrawit Solomon, https://orcid.org/0000-0002-3863-4995

Copyright (C) 2019 Korean Society of Cancer Prevention

(c) This is an Open Access article distributed under the terms of the Creative Commons Attribution Non-Commercial License (http://creativecommons.org/licenses/by-nc/4.0) which permits unrestricted non-commercial use, distribution, and reproduction in any medium, provided the original work is properly cited. 
lung, stomach, liver, colorectal and female breast cancers [6]. These cancers accounted for more than $40 \%$ of all cases diagnosed worldwide. In men, lung cancer was the most common cancer (16.7\% of all new cases in men). Breast cancer was by far the most common cancer diagnosed in women (25.2\% of all new cases in women) [6]. By 2030, it is projected that 26 million new cancer cases and 17 million cancer deaths are expected to occur [7]. This represents an increase of 68\% compared with 2012 (66\% in low and medium human development index [HDI] countries and $56 \%$ in high and very high HDI countries) [6,8]. Moreover, the global distribution of cancer and types of cancer that predominate continues to change, especially in economically developing countries. Low- and middle-income countries accounted for about half (51\%) of all cancers worldwide in 1975 [9]. This proportion increased to $55 \%$ in 2006 and is projected to reach $61 \%$ by 2050 [9]. The global increase in the cancer burden and its disproportionate impact on economically developing countries is being propelled by both demographic changes in the populations at risk and by temporal and geographic shifts in the distribution of major risk factors. Colorectal, lung, female breast and prostate cancers were the main contributors in most regions of the world, explaining $18 \%$ to $50 \%$ of the total healthy years lost [10]. These cancers are no longer largely confined to Western industrialized countries but are among the most common cancers worldwide. An estimated 169.3 million years of healthy life were lost globally because of cancer in 2008 and approximately $44 \%$ of cancer cases and $53 \%$ of cancer deaths occur in countries at a low or medium level of the HDI [11].

In sub-Saharan Africa, cancer burden is predicted to increase by $85 \%$ by 2030 due to the increase in life expectancy, changes in diet and lifestyle and lower burden of communicable diseases [5]. According to the International Agency for Research on Cancer, about 715,000 new cancer cases and 542,000 cancer deaths occurred in 2008 in Africa. These numbers are projected to nearly double (1.28 million new cancer cases and 970,000 cancer deaths) by 2030 simply due to the aging and growth of the population [12]. With the potential to be even higher because of the adoption of behaviors and lifestyles associated with economic development, such as smoking, unhealthy diet, and physical inactivity [13].

Despite this growing burden, cancer continues to receive low public health priority in Africa, largely because of limited resources and other pressing public health problems, including communicable diseases, such as acquired immune deficiency syndrome (AIDS)/human immunodeficiency virus (HIV) infection, malaria, and tuberculosis [14]. It may also be in part due to a lack of awareness about the magnitude of the current and future cancer burden among policy makers, healthcare providers, the general public, and international private or public health agencies [14].

Ethiopia is home to a growing population of more than 105 million people and is the second most populous country in Africa and is expected to become the ninth most populous country in the world by 2050, with an estimated parallel rise in cancer burden [15]. In Ethiopia, cancer is estimated to account for about $5.8 \%$ of total national mortality [16]. Although population-based data do not exist in the country except for Addis Ababa, it is estimated that the annual incidence of cancer is around 60,960 cases and the annual mortality is over 44,000 [16]. For people under the age of 75 years, the risk of being diagnosed with cancer is $11.3 \%$ and the risk of dying from the disease is $9.4 \%$ a five year prevalence for 2003 to 2008 was 224.2 per 100,000 people [17]. The most prevalent cancers in Ethiopia among the adult population are breast cancer (30.2\%), cancer of the cervix (13.4\%), and colorectal cancer (5.7\%). About two-thirds of reported annual cancer deaths occur among women [16]. Based on 2013 data from the Addis Ababa Cancer Registry, breast cancer accounted for $31.4 \%$, cervical cancer for $14.3 \%$ and ovarian cancer for $6.3 \%$ of all cancer cases [18]. According to a qualitative study at the only oncology center in the country at Tikur Anbessa Specialized Hospital, limited patient awareness along with lack of resources contribute to diagnoses of cancers at advanced stages, which lead to poor patient outcomes [19]. However, patterns of cancer, their stages and risk factors for advanced cancers have not been well studied and documented in Ethiopia, as prior studies have largely focused on communicable diseases, such as AIDS/HIV, malaria, and tuberculosis [20]. To fill this substantial gap, this study examines patterns of cancer occurrence and stages of cancer at diagnosis, and risk factors associated with advanced stage cancers among patients at Tikur Anbessa Hospital from 2010 to 2014.

\section{MATERIALS AND METHODS}

\section{Study design and setting}

A hospital-based retrospective cross-sectional study was conducted based on medical record review of selected patients at Tikur Anbessa Hospital in Addis Ababa, Ethiopia. Tikur Anbessa Hospital is Ethiopia's highest tertiary level referral and teaching hospital, and the nation's sole cancer referral center. It is staffed with the nation's most senior specialists and faculty from Addis Ababa University. Tikur Anbessa Hospital is a training center for undergraduate and postgraduate medical students, dentists, nurses, pharmacists, and public health specialists. The hospital 
serves approximately 370,000 to 400,000 patients a year and the emergency department sees around 80,000 patients a year. This study was conducted at pathology department of the school of medicine at Tikur Anbessa Hospital. Before starting data collection ethical approval letter was obtained for data collection from Jimma University (Ethical clearance letter number RPGC/3061/2015).

\section{Study population}

The inclusion criteria were all sampled patients who were diagnosed to have cancer by biopsy at Tikur Anbessa Hospital pathology department between January 1st, 2010 and December 15th, 2014. The exclusion criteria were inconsistency of data among all of the three data sources (biopsy logbook, the physician biopsy request forms and patient cards), if data was not found in all of the three data sources, if the data of a patient was recorded in previous records and if the result of the diagnosis was non-cancerous or a benign lesion.

\section{Sampling procedures}

All samples are given biopsy numbers in the biopsy logbook by calendar year, starting in January and ending in December. The samples were selected by stratified sampling technique considering each of the study years as strata and calculating the samples to be selected from each stratum to be proportional to their size. These samples from each stratum were then included in the study using simple random sampling method using randomly generated numbers.

\section{Sample size calculation}

Sample size is calculated using formula for single and finite population.

$$
\begin{aligned}
& \mathrm{Nf}=\underline{\mathrm{N}(\mathrm{Z} \alpha / 2)^{2} \mathrm{P}(1-\mathrm{P})} \quad \text { where, } \\
& \mathrm{d}^{2}(\mathrm{~N}-1)+\left(\mathrm{Z} \alpha_{/ 2}\right)^{2} \mathrm{P}(1-\mathrm{P})
\end{aligned}
$$

$\mathrm{Nf}$ is minimum sample size, which was calculated to be 919 samples, where $\mathrm{P}$ is taken from recent report of Addis Ababa Cancer Registry about cancer patterns in which the most common cancer, which is breast cancer and the proportion was 33\% and the least common cancer was esophageal cancer and the proportion was $2 \%$ [21]. $d$ is margin of error which is estimated to be $3 \%$ since $\mathrm{P}$ is less than $0.5 . \mathrm{Z} \alpha / 2$ is the standard normal variable at $1 \alpha \%$ confidence level and $\alpha$ is mostly $5 \%$ at $95 \%$ CI level. $\mathrm{N}$ is population size which is total number of patients having biopsy during the year January 1st, 2010 to December 15th, 2014 is 35,400 .

\section{Operational definitions}

Time to presentation is the time from start of chief complaint up to the first time that the patient seeks medical care.

Type of cancer by site is the diagnosis of cancer after biopsy and is expressed by site of occurrence and the values include breast cancer, cervical cancer, prostate cancer, ovarian cancer, colorectal cancer, hematologic malignancies including leukemia and lymphoma, lung cancer, gastric cancer, esophageal cancer, liver cancer (hepatoma), skin, bone and soft tissue cancer, retinoblastoma, thyroid cancer, endometrial/genital cancers, bladder cancer, brain cancer, ear, nose and throat cancer, renal cancer, and nephroblastoma.

Stage of cancer at diagnosis is a measure of disease progression, detailing the degree to which the cancer has advanced. Surveillance Epidemiology and End Results (SEER) program has standardized and simplified staging to ensure consistent definitions over time and is used in countries with advanced population based cancer registry programs.

In-situ cancer is an early cancer that is present only in the layers of cells in which it began.

Localized cancer is cancer which is limited to the organ in which it began, without evidence of spread.

Regional cancer is a cancer that has spread beyond the primary site to nearby organs, lymph nodes (LNs) and tissues.

Distant cancer is cancer that has spread from primary site to distant organs.

Unstaged cancer is cancer for which there is not enough information to indicate stage.

Advanced stage of cancer is regional and/or distant cancer.

Dependent variables are stage of cancer (advanced stage of cancer).

Independent variables are age, sex, time of presentation of patients, types of cancer.

\section{Statistical analysis}

Descriptive statistical analysis was performed across the different types of cancers after stratifying by sex. Pearson chi-square test was used for categorical variables. ANOVA and $t$-tests were computed for continuous variables.

Univariate and multivariate binary logistic regression analyses were performed to examine factors associated with advanced stage cancers. The regression models were built with advanced stage cancers as the outcome variable after adjusting for 
covariates. Covariates were included in the final regression model based on priori and our conceptual framework. Adjusted OR with 95\% CI were used to determine the magnitude of associations among advanced stage cancers and various potential risk factors. Two-tailed statistical significance was assessed at $\alpha<0.05$. All the analyses were conducted in 2019 using statistical software SAS 9.4 (SAS Institute Inc., Cary, NC, USA).

\section{RESULTS}

Table 1 shows basic characteristics of the study participants. Out of the 919 patients in the study, 254 (27.6\%) were males and $665(72.4 \%)$ were females. The overall mean age was $45.2 \pm 19.1$ years and $44.6 \pm 15.1$ years among males and females, respectively. The most common malignancies among males were bone and soft tissue (16.5\%), colorectal (12.2\%), and esophageal (9.1\%). Among females, the most common cancers were cervical (39.7\%), breast (18.3\%), and ovarian (7.1\%). Among both males and females, retinoblastoma and thyroid cancers had the longest time-intervals (in months) between the onset of symptoms and presentation 34.0-19.3 $(P<0.01)$ and 23.3-23.9 $(P<0.01)$, respectively.
Distribution patterns and stages of cancers at diagnosis are provided in Table 2. At the time of diagnosis, 3.9\% and $12.0 \%$ of the malignancies were already distantly metastasized among males and females, respectively. While, regionally metastasized malignancies accounted for $20.9 \%$ in males and $25.6 \%$ in females. Half (50.0\%) of the cancers among males and $45.0 \%$ of the cancers among females were unstageable. Males had less advanced (regional and distant metastasis) stage cancers at diagnosis than females ( $24.8 \%$ vs. $37.6 \%, P<0.01$ ). Among males, $46.7 \%$ of prostate, and $29.0 \%$ of colorectal cancers were at advanced stages at the time of diagnosis. Among females, $59.0 \%$ of breast, $41.7 \%$ of cervical, and $17.2 \%$ of colorectal cancers were at advanced stages at the time of diagnosis.

Table 3 shows the prevalence and risk factors associated with advanced stage cancers stratified by sex. Among females, the odds of having advanced stage malignancy was $221 \%$ (OR $=3.21$; $95 \%$ $\mathrm{CI}=1.69-6.10$ ) higher in those who presented after 12 months, compared to those who presented within 6 months of the onset of symptoms. Among males, Prostate (OR $=5.22 ; 95 \% \mathrm{CI}=$ 1.26-21.60) and breast ( $\mathrm{OR}=9.73 ; 95 \% \mathrm{CI}=2.31-40.92)$ cancers were more likely to be diagnosed at advanced stages, in comparison to bone and soft tissue cancers. Among females,

Table 1. Baseline characteristics and distribution of cancer at diagnosis at Tikur Anbessa Hospital in Ethiopia, 2010 to 2014

\begin{tabular}{|c|c|c|c|c|c|c|}
\hline \multirow{2}{*}{ Site/type of cancer } & \multicolumn{3}{|c|}{ Male } & \multicolumn{3}{|c|}{ Female } \\
\hline & Subject & Age (yr) & $\mathrm{TOP}^{\mathrm{a}}$ & Subject & Age (yr) & $\mathrm{TOP}^{\mathrm{a}}$ \\
\hline All & $254(27.6)$ & $45.2 \pm 19.1$ & $9.7 \pm 8.1$ & $665(72.4)$ & $44.6 \pm 15.1$ & $9.7 \pm 7.1$ \\
\hline Breast & $14(5.5)$ & $52.6 \pm 10.8$ & $11.6 \pm 8.9$ & $122(18.3)$ & $40.6 \pm 12.4$ & $9.4 \pm 6.9$ \\
\hline Cervical & - & - & - & $264(39.7)$ & $48.8 \pm 11.6$ & $8.6 \pm 5.9$ \\
\hline Prostate & $15(5.9)$ & $62.3 \pm 17.7$ & $7.1 \pm 5.4$ & - & - & - \\
\hline Ovarian & - & - & - & $47(7.1)$ & $43.1 \pm 14.4$ & $8.2 \pm 4.7$ \\
\hline Colorectal & $31(12.2)$ & $44.9 \pm 18.1$ & $7.5 \pm 4.5$ & $29(4.4)$ & $50.1 \pm 15.3$ & $8.4 \pm 3.5$ \\
\hline Hematologic & $2(0.8)$ & $58.0 \pm 18.4$ & $3.5 \pm 0.7$ & $3(0.5)$ & $39.3 \pm 23.8$ & $14.3 \pm 8.7$ \\
\hline Lung & $5(2.0)$ & $46.8 \pm 14.5$ & $8.4 \pm 3.0$ & $3(0.5)$ & $49.2 \pm 11.0$ & $7.0 \pm 6.6$ \\
\hline Gastric & $16(6.3)$ & $46.1 \pm 9.9$ & $7.5 \pm 3.3$ & $16(2.4)$ & $49.2 \pm 15.7$ & $7.8 \pm 4.3$ \\
\hline Esophageal & $23(9.1)$ & $50.6 \pm 15.2$ & $8.3 \pm 3.3$ & $37(5.6)$ & $51.8 \pm 11.1$ & $9.4 \pm 4.7$ \\
\hline Liver & $1(0.4)$ & 75.0 & 6.0 & $5(0.8)$ & $32.0 \pm 21.8$ & $4.8 \pm 1.1$ \\
\hline Skin & $15(5.9)$ & $42.7 \pm 19.9$ & $8.4 \pm 9.2$ & $14(2.1)$ & $49.1 \pm 15.1$ & $5.9 \pm 2.5$ \\
\hline Bone and soft tissue & $42(16.5)$ & $37.5 \pm 19.6$ & $10.2 \pm 7.6$ & $33(5.0)$ & $34.6 \pm 17.9$ & $9.0 \pm 7.4$ \\
\hline Retinoblastoma & $6(2.4)$ & $3.8 \pm 1.9$ & $34.0 \pm 11.8$ & $9(1.4)$ & $9.0 \pm 15.5$ & $23.3 \pm 12.9$ \\
\hline Nephroblastoma & $2(0.8)$ & 6.0 & $14.0 \pm 14.1$ & $2(0.3)$ & $5.0 \pm 1.4$ & $9.0 \pm 4.2$ \\
\hline Thyroid & $12(4.7)$ & $42.1 \pm 19.1$ & $19.3 \pm 15.1$ & $31(4.7)$ & $38.3 \pm 17.3$ & $23.9 \pm 17.8$ \\
\hline Renal & $8(3.2)$ & $45.4 \pm 8.5$ & $7.5 \pm 3.6$ & $9(1.4)$ & $29.2 \pm 18.7$ & $8.8 \pm 4.5$ \\
\hline ENT & $18(7.1)$ & $48.2 \pm 15.4$ & $8.4 \pm 6.4$ & $1(0.2)$ & 18.0 & 3.0 \\
\hline Brain & $10(3.9)$ & $24.6 \pm 16.4$ & $7.2 \pm 2.9$ & $4(0.6)$ & $35.0 \pm 16.1$ & $5.5 \pm 2.6$ \\
\hline Bladder & $20(7.9)$ & $58.2 \pm 11.7$ & $6.9 \pm 2.9$ & $10(1.5)$ & $50.3 \pm 12.9$ & $8.2 \pm 3.3$ \\
\hline Endometrial and genital & $6(2.4)$ & $50.0 \pm 13.4$ & $13.7 \pm 6.7$ & $22(3.3)$ & $48.2 \pm 15.1$ & $12.9 \pm 6.8$ \\
\hline Others & $8(3.2)$ & $49.4 \pm 18.1$ & $8.8 \pm 3.7$ & $4(0.6)$ & $29.8 \pm 10.3$ & $8.3 \pm 6.1$ \\
\hline
\end{tabular}

Values are presented as number (\%) or mean \pm SD. ENT, ear, nose and throat; TOP, time of presentation from onset of symptoms in month. ${ }^{a} P<0.01$ using ANOVA. 
Table 2. Stages of cancer at diagnosis at Tikur Anbessa Hospital in Ethiopia, 2010 to 2014

\begin{tabular}{|c|c|c|c|c|c|c|}
\hline Site/type of cancer & Sex & Unstaged (\%) & Localized (\%) & Regional (\%) & Distant (\%) & $\begin{array}{l}\text { Advanced }^{\mathrm{a}} \text { (regional } \\
\text { and distant) (\%) }\end{array}$ \\
\hline \multirow[t]{2}{*}{ All } & Male & 50.0 & 25.2 & 20.9 & 3.9 & 24.8 \\
\hline & Female & 45.0 & 17.4 & 25.6 & 12.0 & 37.6 \\
\hline \multirow[t]{2}{*}{ Breast } & Male & 35.7 & 0.0 & 50.0 & 14.3 & 64.3 \\
\hline & Female & 36.1 & 4.9 & 32.8 & 26.2 & 59.0 \\
\hline \multirow[t]{2}{*}{ Cervical } & Male & - & - & - & - & - \\
\hline & Female & 46.2 & 12.1 & 31.1 & 10.6 & 41.7 \\
\hline \multirow[t]{2}{*}{ Prostate } & Male & 6.7 & 46.7 & 46.7 & 0.0 & 46.7 \\
\hline & Female & - & - & - & - & - \\
\hline \multirow[t]{2}{*}{ Ovarian } & Male & - & - & - & - & - \\
\hline & Female & 38.3 & 19.2 & 23.4 & 19.2 & 42.6 \\
\hline \multirow[t]{2}{*}{ Colorectal } & Male & 54.8 & 16.1 & 22.6 & 6.5 & 29.0 \\
\hline & Female & 48.3 & 34.5 & 13.8 & 3.5 & 17.2 \\
\hline \multirow[t]{2}{*}{ Hematologic } & Male & 100.0 & 0.0 & 0.0 & 0.0 & 0.0 \\
\hline & Female & 100.0 & 0.0 & 0.0 & 0.0 & 0.0 \\
\hline \multirow[t]{2}{*}{ Lung } & Male & 40.0 & 0.0 & 60.0 & 0.0 & 60.0 \\
\hline & Female & 33.3 & 33.3 & 0.0 & 33.3 & 33.3 \\
\hline \multirow[t]{2}{*}{ Gastric } & Male & 81.3 & 6.3 & 6.3 & 6.3 & 12.5 \\
\hline & Female & 50.0 & 37.5 & 12.5 & 0.0 & 12.5 \\
\hline \multirow[t]{2}{*}{ Esophageal } & Male & 56.5 & 17.4 & 17.4 & 8.7 & 26.1 \\
\hline & Female & 59.5 & 18.9 & 21.6 & 0.0 & 21.6 \\
\hline \multirow[t]{2}{*}{ Liver } & Male & 100.0 & 0.0 & 0.0 & 0.0 & 0.0 \\
\hline & Female & 0.0 & 40.0 & 40.0 & 20.0 & 60.0 \\
\hline \multirow[t]{2}{*}{ Skin } & Male & 40.0 & 53.3 & 6.7 & 0.0 & 6.7 \\
\hline & Female & 14.3 & 42.9 & 21.4 & 21.4 & 42.9 \\
\hline \multirow[t]{2}{*}{ Bone and soft tissue } & Male & 64.3 & 14.3 & 21.4 & 0.0 & 21.4 \\
\hline & Female & 75.8 & 21.2 & 0.0 & 3.0 & 3.0 \\
\hline \multirow[t]{2}{*}{ Retinoblastoma } & Male & 16.7 & 50.0 & 16.7 & 16.7 & 33.3 \\
\hline & Female & 0.0 & 55.6 & 44.0 & 0.0 & 44.4 \\
\hline \multirow[t]{2}{*}{ Nephroblastoma } & Male & 0.0 & 50.0 & 50.0 & 0.0 & 50.0 \\
\hline & Female & 0.0 & 50.0 & 50.0 & 0.0 & 50.0 \\
\hline \multirow[t]{2}{*}{ Thyroid } & Male & 41.7 & 41.7 & 16.7 & 0.0 & 16.7 \\
\hline & Female & 25.8 & 45.2 & 25.8 & 3.2 & 29.0 \\
\hline \multirow[t]{2}{*}{ Renal } & Male & 37.5 & 37.5 & 25.0 & 0.0 & 25.0 \\
\hline & Female & 22.2 & 55.6 & 22.2 & 0.0 & 22.2 \\
\hline \multirow[t]{2}{*}{ ENT } & Male & 66.7 & 11.1 & 16.7 & 5.6 & 22.2 \\
\hline & Female & 0.0 & 0.0 & 100.0 & 0.0 & 100.0 \\
\hline \multirow[t]{2}{*}{ Brain } & Male & 10.0 & 80.0 & 10.0 & 0.0 & 10.0 \\
\hline & Female & 75.0 & 25.0 & 0.0 & 0.0 & 0.0 \\
\hline \multirow[t]{2}{*}{ Bladder } & Male & 25.0 & 55.0 & 15.0 & 5.0 & 20.0 \\
\hline & Female & 30.0 & 40.0 & 20.0 & 10.0 & 30.0 \\
\hline \multirow[t]{2}{*}{ Endometrial and genital } & Male & 100.0 & 0.0 & 0.0 & 0.0 & 0.0 \\
\hline & Female & 90.9 & 0.0 & 0.0 & 9.1 & 9.1 \\
\hline \multirow[t]{2}{*}{ Others } & Male & 87.5 & 0.0 & 12.5 & 0.0 & 12.5 \\
\hline & Female & 100.0 & 0.0 & 0.0 & 0.0 & 0.0 \\
\hline
\end{tabular}

ENT, ear, nose and throat. ${ }^{a} P=0.04$ among males; $P<0.01$ among females, and all males verses females using chi-square test.

breast (OR $=1.93 ; 95 \% \mathrm{CI}=1.23-3.03)$ cancer was more likely to be diagnosed at advanced stages, while colorectal ( $O R=0.30 ; 95 \%$ $\mathrm{CI}=0.11-0.83)$, gastric $(\mathrm{OR}=0.20 ; 95 \% \mathrm{CI}=0.04-0.90)$, esophageal ( $\mathrm{OR}=0.39 ; 95 \% \mathrm{CI}=0.17-0.90)$, bone and soft tissue $(\mathrm{OR}=0.04 ; 95 \% \mathrm{CI}=0.01-0.29)$, thyroid $(\mathrm{OR}=0.30 ; 95 \% \mathrm{CI}=$ $0.12-0.78)$, and endometrial and genital $(\mathrm{OR}=0.11 ; 95 \% \mathrm{CI}=$
0.02-0.48) cancers were less likely to be diagnosed at advanced stages, in comparison to cervical cancers.

The distribution of cancer at diagnosis by age group stratified by sex at Tikur Anbessa Hospital in Ethiopia, 2010 to 2014 is illustrated Table 4.

Selected cancers with high incidence rates and related factors 
Table 3. Prevalence and risk factors associated with advanced stage cancers stratified by sex at diagnosis at Tikur Anbessa Hospital in Ethiopia, 2010 to 2014

\begin{tabular}{|c|c|c|c|c|c|c|c|}
\hline & \multirow{3}{*}{ Variable } & \multicolumn{6}{|c|}{ Advanced stage $^{a}$ cancer } \\
\hline & & \multicolumn{3}{|c|}{ Male } & \multicolumn{3}{|c|}{ Female } \\
\hline & & Prevalence (\%) & OR & $(95 \% \mathrm{CI})$ & Prevalence (\%) & OR & $(95 \% \mathrm{CI})$ \\
\hline \multirow[t]{3}{*}{ Age (yr) } & $<30$ & 28.6 & & 1.00 & 33.7 & & 1.00 \\
\hline & $30-59$ & 25.2 & 0.60 & $(0.24-1.48)$ & 39.4 & 0.95 & $(0.52-1.75)$ \\
\hline & $\geq 60$ & 21.1 & 0.37 & $7(0.13-1.08)$ & 34.1 & 0.89 & $(0.44-1.81)$ \\
\hline \multirow[t]{3}{*}{ TOP (mo) } & $<6$ & 22.4 & & 1.00 & 36.7 & & 1.00 \\
\hline & $6-12$ & 29.1 & 1.35 & $(0.69-2.68)$ & 34.7 & 1.03 & $(0.71-1.49)$ \\
\hline & $>12$ & 16.7 & 0.40 & $(0.09-1.74)$ & 52.6 & 3.21 & $(1.69-6.10)$ \\
\hline \multirow[t]{21}{*}{ Cancer type/site } & Breast & 64.3 & 9.73 & $(2.31-40.92)$ & 59.0 & 1.93 & $(1.23-3.03)$ \\
\hline & Cervical & $\mathrm{N} / \mathrm{A}$ & & $\mathrm{N} / \mathrm{A}$ & 41.7 & & 1.00 \\
\hline & Prostate & 46.7 & 5.22 & $(1.26-21.60)$ & $\mathrm{N} / \mathrm{A}$ & & $\mathrm{N} / \mathrm{A}$ \\
\hline & Ovarian & $\mathrm{N} / \mathrm{A}$ & & $\mathrm{N} / \mathrm{A}$ & 42.6 & 1.07 & $(0.56-2.03)$ \\
\hline & Colorectal & 29.0 & 1.78 & $(0.58-5.52)$ & 17.2 & 0.30 & $(0.11-0.83)$ \\
\hline & Hematologic & 0.0 & & -- & 0.0 & & -- \\
\hline & Lung & 60.0 & 5.67 & $(0.79-40.90)$ & 33.3 & 0.51 & $(0.04-6.26)$ \\
\hline & Gastric & 12.5 & 0.62 & $(0.11-3.51)$ & 12.5 & 0.20 & $(0.04-0.90)$ \\
\hline & Esophageal & 26.1 & 1.60 & $(0.45-5.65)$ & 21.6 & 0.39 & $(0.17-0.90)$ \\
\hline & Liver & 0.0 & & -- & 60.0 & 2.26 & $(0.36-14.14)$ \\
\hline & Skin & 6.7 & 0.33 & $(0.04-3.02)$ & 42.9 & 1.16 & $(0.39-3.47)$ \\
\hline & Bone and soft tissue & 21.4 & & 1.00 & 3.0 & 0.04 & $(0.01-0.29)$ \\
\hline & Retinoblastoma & 33.3 & 3.56 & $(0.36-35.36)$ & 44.4 & 0.52 & $(0.11-2.43)$ \\
\hline & Nephroblastoma & 50.0 & 4.53 & $(0.22-8.80)$ & 50.0 & 1.44 & $(0.08-24.82)$ \\
\hline & Thyroid & 16.7 & 1.05 & $5(0.18-6.09)$ & 29.0 & 0.30 & $(0.12-0.78)$ \\
\hline & Renal & 25.0 & 1.40 & $(0.22-8.80)$ & 22.2 & 0.36 & $(0.07-1.86)$ \\
\hline & ENT & 22.2 & 1.37 & $7(0.34-5.57)$ & 100.0 & & -- \\
\hline & Brain & 10.0 & 0.32 & $(0.04-2.90)$ & 0.0 & & -- \\
\hline & Bladder & 20.0 & 1.39 & $(0.33-5.88)$ & 30.0 & 0.66 & $(0.17-2.60)$ \\
\hline & Endometrial and genital & 0.0 & & -- & 9.1 & 0.11 & $(0.02-0.48)$ \\
\hline & Others & 12.5 & 0.58 & $(0.06-5.63)$ & 0.0 & & -- \\
\hline
\end{tabular}

TOP, time of presentation from onset of symptom in months; ENT, ear nose and throat; N/A, non-applicable; --, not enough sample size to compute OR, ${ }^{a}$ Regional or distant metastasis.

are shown in Table 5.

\section{DISCUSSION}

The majority of the biopsy-confirmed cancer diagnoses were made in females. We found bone and soft tissue (16.5\%), colorectal (12.2\%), and esophageal (9.1\%) were the most common cancer diagnoses among males. Among females, the most common cancers were cervical (39.7\%), breast (18.3\%), and ovarian (7.1\%). At the time of diagnosis, $3.9 \%$ and $12.0 \%$ of the malignancies were already distantly metastasized among males and females, respectively. Advanced stage cancers were more common among females than males at the time of diagnosis. Prostate and breast cancers among males, and breast cancer among females were more likely to be diagnosed at advanced stages. Significant proportions of cervical and colorectal cancers were also diagnosed at advanced stages. Delayed presentation from onset of symptom was associated with more advanced stage cancer diagnoses among females.

Our study found the majority of patients with cancer were females (72.4\%) with mean age of $44.6 \pm 15.1$ years. This finding concurs with a recent report of Addis Ababa cancer registry, where $67 \%$ of the registered cancer cases were women with highest incidence rate of $38.4 \%$ in the age group of 30 to 49 years [21]. Similarly, higher burden of cancer among females have been reported in other African countries [6,22]. A possible explanation could be the fact that females are more likely to be in contact with clinicians and utilize health services, largely due to pregnancy and childbirth [23]. Occurrence of different malignancies among females especially those related to reproductive organs could be the reason for this sex preference and the age group preference could be due to repeated exposure of these reproductive age 
Table 4. Distribution of cancer at diagnosis by sex and age group at Tikur Anbessa Hospital in Ethiopia, 2010 to 2014

\begin{tabular}{|c|c|c|c|c|c|c|}
\hline \multirow{2}{*}{ Site/type of cancer } & \multicolumn{3}{|c|}{ Male $^{\mathrm{a}}$} & \multicolumn{3}{|c|}{ Female $^{\mathrm{a}}$} \\
\hline & Age $(<30 \mathrm{yr})$ & Age $(30-59$ yr) & Age $(\geq 60 \mathrm{yr})$ & Age $(<30 \mathrm{yr})$ & Age (30-59 yr) & Age $(\geq 60 \mathrm{yr})$ \\
\hline All & 22.1 & 50.0 & 27.9 & 13.8 & 66.8 & 19.4 \\
\hline Breast & 0.0 & 71.4 & 28.6 & 14.8 & 75.4 & 9.8 \\
\hline Cervical & - & - & - & 2.7 & 74.6 & 22.7 \\
\hline Prostate & 13.3 & 13.3 & 73.3 & - & - & - \\
\hline Ovarian & - & - & - & 19.2 & 65.9 & 14.9 \\
\hline Colorectal & 19.4 & 54.8 & 25.8 & 3.5 & 68.9 & 14.9 \\
\hline Hematologic & 0.0 & 50.0 & 50.0 & 33.3 & 33.3 & 33.3 \\
\hline Lung & 20.0 & 60.0 & 20.0 & 0.0 & 66.7 & 33.3 \\
\hline Gastric & 0.0 & 87.5 & 12.5 & 12.5 & 56.3 & 31.2 \\
\hline Esophageal & 8.7 & 56.5 & 34.8 & 0.0 & 64.9 & 35.1 \\
\hline Liver & 0.0 & 0.0 & 100.0 & 40.0 & 60.0 & 0.0 \\
\hline Skin & 26.7 & 53.3 & 20.0 & 7.1 & 64.3 & 28.6 \\
\hline Bone and soft tissue & 45.2 & 40.5 & 14.3 & 45.5 & 39.4 & 15.1 \\
\hline Retinoblastoma & 100.0 & 0.0 & 0.0 & 88.9 & 11.1 & 0.0 \\
\hline Nephroblastoma & 100.0 & 0.0 & 0.0 & 100.0 & 0.0 & 0.0 \\
\hline Thyroid & 33.3 & 41.7 & 25.0 & 38.7 & 51.6 & 9.7 \\
\hline Renal & 0.0 & 87.5 & 12.5 & 44.4 & 55.6 & 0.0 \\
\hline ENT & 11.1 & 61.1 & 27.8 & 100.0 & 0.0 & 0.0 \\
\hline Brain & 70.0 & 30.0 & 0.0 & 50.0 & 50.0 & 0.0 \\
\hline Bladder & 0.0 & 40.0 & 60.0 & 10.0 & 60.0 & 30.0 \\
\hline Endometrial and genital & 0.0 & 66.7 & 33.3 & 18.2 & 50.0 & 31.8 \\
\hline Others & 12.5 & 50.0 & 37.5 & 50.0 & 50.0 & 0.0 \\
\hline
\end{tabular}

Values are presented as percent only. ENT, ear nose and throat. ${ }^{a} P<0.01$.

group population with different risk factors related to cancer [21]. Particular attention needs to be paid to this issue since predominantly the productive age groups, mainly females, are being affected, which in turn could have an impact on the economy of the country.

Results of this study showed the most common cancers among females were cervical (39.7\%), breast (18.4\%), and ovarian (7.1\%). These three top cancers were also reported by the Addis Ababa cancer registry report where the most common cancers in females were cancer of the breast 33\%, followed by cancer of the cervix uteri $17 \%$ and ovary $6 \%$ [21]. These findings are also similar with studies done about pattern and trends of cancer in Odisha, India and in South Africa except that breast cancer in these countries is the most common cancer diagnosis [24,25]. In India carcinomas of breast (28.94\%), cervix (23.66\%), and ovary (16.11\%) are leading causes among females and breast cancer was the leading cause of cancer followed by cervical cancer and colorectal cancer in South Africa $[24,25]$. This similarity could be explained by the similarity of the social and economic context of these countries, as well as due to lack of awareness of patients about the symptoms of cancer in these countries. The significant burden of cervical cancer has been attributed to the high prevalence of human papilloma virus (HPV) infection coupled with a lack of screening services for prevention and early detection of the disease [26].

In the Global Cancer Incidence, Mortality and Prevalence (GLOBOCAN) 2012 report, the most commonly diagnosed cancers worldwide are those of the lung $13.0 \%$, breast $11.9 \%$, and colorectal 9.7\% [5]. These differences from our study findings are mainly due to the disparity in standards of living between developed and developing countries, high prevalence of infections related to cancers especially cervical cancer in developing countries and increased lifestyle risk factors related to cancers, mainly smoking, in developed countries. This implies that in Ethiopia the risk could significantly increase in the near future since there is high prevalence of infection related cancers coupled with adoption of western lifestyle in the country [27]. In addition, these findings imply problem in the awareness among the general public regarding cancer or problem in availability and utilization of early screening modalities [26,28].

The study found the most common malignancies among males were bone and soft tissue (16.5\%), colorectal (12.2\%), and esophageal (9.1\%) with some similarity with the report of the Addis Ababa cancer registry where colorectal cancer was the leading cancer among males at 19\% [21]. However, the result is different from the study at Yirga Alem Hospital where the most common cancers by site in men were non-Hodgkin's lymphoma 
Table 5. Selected high incident cancers, bone and soft tissue cancer and colorectal in males and cervical and breast cancer in $\mathrm{fe}$ males, and related factors at diagnosis at Tikur Anbessa Hospital in Ethiopia, 2010 to 2014

\begin{tabular}{|c|c|c|}
\hline \multicolumn{2}{|l|}{ Variable } & Value \\
\hline \multicolumn{3}{|l|}{ Male } \\
\hline \multicolumn{3}{|l|}{ Bone and soft tissue } \\
\hline \multirow[t]{3}{*}{$\mathrm{TOP}(\mathrm{mo})^{\mathrm{a}}$} & $<6$ & 33.30 \\
\hline & $6-12$ & 52.40 \\
\hline & $>12$ & 14.30 \\
\hline \multirow[t]{4}{*}{ Chief presenting complaints ${ }^{\mathrm{a}}$} & Difficulty walking & 52.40 \\
\hline & $\begin{array}{l}\text { Soft tissue } \\
\text { swelling }\end{array}$ & 11.90 \\
\hline & $\begin{array}{l}\text { Difficulty } \\
\text { swallowing }\end{array}$ & 2.40 \\
\hline & Others & 33.30 \\
\hline \multicolumn{3}{|l|}{ Colorectal cancer } \\
\hline \multirow[t]{3}{*}{ TOP $(\mathrm{mo})^{\mathrm{a}}$} & $<6$ & 54.80 \\
\hline & $6-12$ & 41.90 \\
\hline & $>12$ & 3.20 \\
\hline \multirow[t]{4}{*}{ Chief presenting complaints ${ }^{\mathrm{a}}$} & Constipation & 45.20 \\
\hline & Abdominal pain & 12.90 \\
\hline & Diarrhea & 12.90 \\
\hline & Others & 29.00 \\
\hline \multicolumn{3}{|l|}{ Female } \\
\hline \multicolumn{3}{|l|}{ Cervical cancer } \\
\hline \multirow[t]{3}{*}{$\mathrm{TOP}(\mathrm{mo})^{\mathrm{a}}$} & $<6$ & 42.40 \\
\hline & $6-12$ & 49.60 \\
\hline & $>12$ & 12.30 \\
\hline \multirow[t]{4}{*}{ Chief presenting complaints* } & Vaginal bleeding & 54.90 \\
\hline & $\begin{array}{l}\text { Post-coital } \\
\text { bleeding }\end{array}$ & 17.80 \\
\hline & Abdominal pain & 5.30 \\
\hline & Others & 22.00 \\
\hline \multicolumn{3}{|l|}{ Breast cancer } \\
\hline \multirow[t]{3}{*}{ TOP $(\mathrm{mo})^{\mathrm{a}}$} & $<6$ & 39.30 \\
\hline & $6-12$ & 48.40 \\
\hline & $>12$ & 12.30 \\
\hline \multirow[t]{4}{*}{ Chief presenting complaints ${ }^{\mathrm{a}}$} & $\begin{array}{l}\text { Breast lump and } \\
\text { swelling }\end{array}$ & 45.10 \\
\hline & $\begin{array}{l}\text { Ulcerative breast } \\
\text { lesion }\end{array}$ & 37.70 \\
\hline & Pain & 6.60 \\
\hline & Others & 10.60 \\
\hline
\end{tabular}

Values are presented as percent only. TOP, time of presentation from onset of symptom in months. ${ }^{a} P<0.01$.

(13.9\%), soft-tissue sarcoma (12.7\%), and non-melanoma skin cancer (12.2\%) [29]. The reason for this disparity could be the difference in the study period since the study was done 20 years ago where non-Hodgkin's lymphoma was much more common due to high prevalence of HIV/AIDS at that time [29]. Some of these findings could also be due the relative ease of being able to obtain and confirm these types of cancers in resource limited settings, compared to other cancer types, which may require more technical expertise and invasive procedures.

We found esophageal cancer is the third most common cancer among males in Ethiopia. Although other cancer studies in Ethiopia have not reported similar findings, esophageal cancer is common among several East African countries [30]. Studies have reported Malawi has the highest incidence rates in the world, while esophageal cancer is the leading cause of cancer mortality among men in Kenya [30]. The underlying risk factors vary greatly from tobacco smoking and heavy alcohol drinking in Western countries to drinking hot mate in South America. The cause for relatively high esophageal cancer rates in East Africa, including Ethiopia is unclear, given the relatively low rates of tobacco smoking and heavy alcohol drinking [30,31]. One possible explanation that needs to be further investigated is the high prevalence of Khat chewing among males in Ethiopia [31]. Khat is a stimulant containing Alkaloid Cathinone that has been linked to genetic tissue damage and esophageal cancer [32].

Overall, males had less advanced stage cancers at diagnosis than females (24.8\% vs. $37.6 \%, P<0.01)$. Among females $59.0 \%$ of the breast cancers were at advanced stages at the time of diagnosis. This finding is in contrast to lower advanced stage breast cancer rates at diagnosis in developing countries, such as the recently reported $46.0 \%$ in the Netherlands [33]. This is likely to be multifactorial, including lack of awareness about cancer among females or ignoring what they think is minor symptoms because of their low economic status or social stigma. This result is similar with a study published in Lancet in 2013, where patients often present with aggressive features; concluding Ethiopian women with breast cancer often ignore lumps, and usually seek treatment only when symptoms such as pain and itching occur [15].

Among females, the odds of having advanced stage malignancy was 3.21 times higher in those who presented more than a year after having the first symptom compared to those with shorter presentation within 6 months and Breast cancer was more likely to be diagnosed at advanced stage. This is also comparable with a study done on the influence on survival of delay in the presentation and treatment of symptomatic breast cancer, where $32 \%$ of patients had symptoms for 12 or more weeks before their first hospital visit and $32 \%$ of patients with delays of 12 or more weeks had locally advanced or metastatic disease, compared with only $10 \%$ of those with delays of less than 12 weeks $(P<0.0001)$ [34].

Significant proportion (41.7\%) of cervical cancers were also diagnosed at advanced stages, which previous studies have attributed to several factors, including lack of awareness and 
access to appropriate health services, and the use of traditional remedies for early stages of the disease [32]. The cancer stage at presentation will have impact not only on the treatment outcome and survival of patients, but also on costs related to treatment and follow ups. Substantial progress could be made through effective public health education, along with HPV vaccine and HPV-based cervical cancer screening programs [35].

In both males and females, retinoblastoma and thyroid cancers had the longest time-intervals between the onset of symptoms and presentation. This is in contrast to a study conducted in England on risk factors for delay in symptomatic presentation of cancer, prostate (44\%) and rectal cancers (37\%) were most likely to delay and patients with breast cancer least likely to delay (8\%) [36]. In our study, we did find prostate cancer was most likely to be diagnosed at more advanced stage. On the contrary, diagnosis of advanced stage prostate cancer has been declining in developed counties, such as the United Kingdom [37]. This is likely due to the difference in the cancer patterns and having the awareness and access to appropriate medical care to diagnose symptomatic cancers, such as prostate, thyroid and breast cancers in developed countries.

The study has several strengths. First, cancer diagnoses were confirmed with biopsy, as opposed to diagnoses made solely clinically or from patient surveys. Second, the study was conducted at Tikur Anbessa Hospital, the country's sole cancer referral center. Finally, a large representative sample size was used over a 5-year time-period. One of the study limitations is the fact that it was based on patients who were able to have a biopsy done. Many factors could influence this, including whether or not a patient was able to present to appropriate medical facility and obtained a timely referral to Tikur Anbessa Hospital. It also depends on whether or not the patient was able to undergo a biopsy and on the availability of equipment and technical expertise in a low resource country. Finally, nearly half of the cancers were unstageable. These limitations could underestimate certain types of cancers and should be considered when interpreting the study findings and future studies should be designed to identify factors associated with common cancer occurrences in Ethiopia.

In conclusion, we found cancers with effective screening tests, such as cervical, breast and colorectal cancers are common in Ethiopia and significant proportions of these were diagnosed at advanced stages, typically several months after onset of symptoms. Timely access to preventive care along with effective educational and screening strategies is needed in Ethiopia to detect and treat cancer early.

\section{CONFLICTS OF INTEREST}

No potential conflicts of interest were disclosed.

\section{REFERENCES}

1. Misganaw A, Mariam DH, Ali A, Araya T. Epidemiology of major non-communicable diseases in Ethiopia: a systematic review. J Health Popul Nutr 2014:32:1-13.

2. Alwan A, Maclean DR, Riley LM, d'Espaignet ET, Mathers CD, Stevens GA, et al. Monitoring and surveillance of chronic non-communicable diseases: progress and capacity in high-burden countries. Lancet 2010;376:1861-8.

3. World Health Organization. Global status report on noncommunicable diseases. Geneva, World Health Organization, $p$ 162, 2011.

4. World Health Organization. Noncommunicable diseases country profiles. Geneva, World Health Organization, p 207, 2011.

5. American Cancer Society. The history of cancer. https:// www.cancer.org/cancer/cancer-basics/history-of-cancer.html. Accessed June 18, 2019.

6. Ferlay J, Soerjomataram I, Ervik M, Dikshit R, Eser S, Mathers C, et al. GLOBOCAN 2012: Estimated cancer incidence, mortality and prevalence worldwide in 2012 v1.0. https://publications. iarc.fr/Databases/Iarc-Cancerbases/GLOBOCAN-2012-Estimated-C ancer-Incidence-Mortality-And-Prevalence-Worldwide-In-2012V1.0-2012. Accessed June 18, 2019.

7. Boyle $\mathrm{P}$, Levin $\mathrm{BE}$. International agency for research on cancer: world cancer report. Lyon, IARC Press, 2008.

8. Bray F, Jemal A, Grey N, Ferlay J, Forman D. Global cancer transitions according to the Human Development Index (2008-2030): a population-based study. Lancet Oncol 2012;13:790-801.

9. Bray F, Møller B. Predicting the future burden of cancer. Nat Rev Cancer 2006;6:63-74.

10. Soerjomataram I, Lortet-Tieulent J, Parkin DM, Ferlay J, Mathers C, Forman D, et al. Global burden of cancer in 2008: a systematic analysis of disability-adjusted life-years in 12 world regions. Lancet 2012;380:1840-50.

11. United Nations Development Programme. Human development report. New York, United Nations, 2013.

12. Ferlay J, Shin HR, Bray F, Forman D, Mathers CD, Parkin D. GLOBOCAN 2008: Cancer incidence and mortality worldwide: IARC Cancer-Base No.10. https://www.iarc.fr/media-centre-iarc-news-29/. Accessed June 18, 2019.

13. World Health Organization. World cancer report 2008. Lyon, International Agency for Research on Cancer, 2008.

14. Parkin DM, Sanghvi LD. Cancer registration in developing countries. In: Jensen OM, Parkin DM, MacLennan R, Muir CS, Skeet RG, eds. Cancer registration: principles and methods. Lyon, IARC Scientific Publications, pp 185-198, 1991.

15. Woldeamanuel YW, Girma B, Teklu AM. Cancer in Ethiopia. Lancet Oncol 2013;14:289-90.

16. Federal Ministry of Health Ethiopia. National Cancer Control Plan 2016-2020. https://www.iccp-portal.org/sites/default/files/plans/ NCCP\%20Ethiopia\%20Final\%20261015.pdf. Accessed June 18, 2019.

17. GLOBOCAN 2008. Fast facts: less developed regions. Geneva, IARC, 
2008. http://globocan.iarc.fr/factsheets/populations/factsheet.asp? uno $=902$. Accessed June 18, 2019 .

18. Memirie ST, Habtemariam MK, Asefa M, Deressa BT, Abayneh G, Tsegaye B, et al. Estimates of cancer incidence in Ethiopia in 2015 using population-based registry data. J Glob Oncol 2018:4:1-11.

19. Haileselassie W, Mulugeta T, Tigeneh W, Kaba M, Labisso WL. The situation of cancer treatment in Ethiopia: challenges and opportunities. J Cancer Prev 2019;24:33-42.

20. World Health Organization. Preventing chronic diseases: a vital investment. Geneva, World Health Organization, 2005.

21. Addis Ababa City Cancer Registry. Cancer incidence in Addis Ababa. Addis Ababa, Addis Ababa population based cancer registry, 2014. Addis Ababa, Tikur Anbessa Specialized Hospital, 2014.

22. Wabinga HR, Nambooze S, Amulen PM, Okello C, Mbus L, Parkin DM. Trends in the incidence of cancer in Kampala, Uganda 1991-2010. Int J Cancer 2014:135:432-9.

23. Mustard CA, Kaufert P, Kozyrskyj A, Mayer T. Sex differences in the use of health care services. N Engl J Med 1998;338:1678-83.

24. Hussain MA, Pati S, Swain S, Prusty M, Kadam S, Nayak S. Pattern and trends of cancer in odisha, India: a retrospective study. Asian Pac J Cancer Prev 2012;13:6333-6.

25. Albrecht $C$. Overview of the South African cancer research environment. Cancer Research Initiative of South Africa. University of Cape Town, Cape Town, 2006.

26. Birhanu Z, Abdissa A, Belachew T, Deribew A, Segni H, Tsu V, et al. Health seeking behavior for cervical cancer in Ethiopia: a qualitative study. Int J Equity Health 2012;11:83.

27. Sylla BS, Wild CP. A million Africans a year dying from cancer by 2030: what can cancer research and control offer to the continent? Int J Cancer 2012;130:245-50.

28. De Ver Dye T, Bogale S, Hobden C, Tilahun Y, Hechter V, Deressa
T, et al. A mixed-method assessment of beliefs and practice around breast cancer in Ethiopia: implications for public health programming and cancer control. Glob Public Health 2011;6: 719-31.

29. Ashine S, Lemma B. Malignant tumours at Yirga Alem Hospital. Ethiop Med J 1999:37:163-72.

30. Bray F, Ferlay J, Soerjomataram I, Siegel RL, Torre LA, Jemal A. Global cancer statistics 2018: GLOBOCAN estimates of incidence and mortality worldwide for 36 cancers in 185 countries. CA Cancer J Clin 2018;68:394-424.

31. Tran A, Gelaye B, Girma B, Lemma S, Berhane Y, Bekele T, et al. Prevalence of metabolic syndrome among working adults in Ethiopia. Int J Hypertens 2011;2011:193719.

32. Gunaid AA, Sumairi AA, Shidrawi RG, al-Hanaki A, al-Haimi M, al-Absi S, et al. Oesophageal and gastric carcinoma in the Republic of Yemen. Br J Cancer 1995:71:409-10.

33. Vondeling GT, Menezes GL, Dvortsin EP, Jansman FGA, Konings IR, Postma MJ, et al. Burden of early, advanced and metastatic breast cancer in The Netherlands. BMC Cancer 2018;18:262.

34. Richards MA, Smith P, Ramirez AJ, Fentiman IS, Rubens RD. The influence on survival of delay in the presentation and treatment of symptomatic breast cancer. Br J Cancer 1999;79:858-64.

35. Lowndes $\mathrm{CM}$. Vaccines for cervical cancer. Epidemiol Infect 2006;134:1-12.

36. Forbes LJ, Warburton F, Richards MA, Ramirez AJ. Risk factors for delay in symptomatic presentation: a survey of cancer patients. Br J Cancer 2014;111:581-8.

37. National Collaborating Centre for Cancer (UK). Prostate cancer: diagnosis and treatment. Cardiff (UK), National Collaborating Centre for Cancer (UK), 2014. 